\title{
Phenomenological Model of Particulate Matter Emission from Direct Injection Diesel Engines
}

Departamento de Engenharia Mecânica Av. Humberto de Alencar Castelo Branco, 3972 09850-901 São Bernardo do Campo SP. Brazil celsoarj@fei.edu.br

\section{A. P. Pimenta}

ITA - Instituto Tecnológico de Aeronáutica Divisão de Engenharia Aeronáutica Praça Marechal Eduardo Gomes, 50 12228-900 São José dos Campos, SP. Brazil amilcar@aer.ita.br
A new phenomenological model is introduced by applying established conceptual models for direct injection combustion to develop a mathematical description of events. The model has the capability to predict particulate mass output, as well as a particulate mass history over a single combustion event. The model was developed in a Matlab-Simulink environment to promote modularity. Results of particulate mass output from single cylinder laboratory engine, and six-cylinder vehicular engine were used to determine the validity of the predictions made. Although predicted values do not perfectly match measured values, there is certainly reasonable agreement.

Keywords: Diesel engines, particulate emission, combustion chamber, fuel injection

\section{Introduction}

Particulate matter, or soot, is one of the major pollutants produced by diesel engines. The other major pollutant is nitrogen oxide $\left(\mathrm{NO}_{\mathrm{X}}\right)$. Soot, particularly small particles, has been show to be a health hazard. The small particles can penetrate deeply into lung tissues. Because oxides of nitrogen and the particulates can not be easily reduced simultaneously without degrading the engine performance, they are the most critical pollutants. The overall objective of this research is to utilize current understandings presented from modern methods of experimentation to develop a new phenomenological model of particulate emissions that is flexible, computationally inexpensive, while maintaining reasonable fidelity. The model is developed based on a modular philosophy, in a Matlab-Simulink environment, and does not utilize a finite element or zonal approach. The conditions required by the model include: in cylinder pressure, mass rate of fuel injection, injection velocity, bulk mean temperature, energy release rate, and the characteristics of injector nozzles. With this information the model predicts: general geometry of developed spray plume, general temperature distribution, mass history of particulate matter in the combustion chamber, and mass of particulate matter expunged from the cylinder. The model is developed as a tool to be utilized by researches and designers in investigations of operating conditions that decrease the particulate matter output of direct injection engines, with user friendliness, flexibility and modularity. This new model can operate either as a stand-alone device for predicting particulate matter output from a direct injection engine, or as a submodel in a larger system model of a modern Diesel engine.

\section{Nomenclature}

$$
\begin{aligned}
& \mathrm{a}=\text { Empirical constant, } 0.66 \text { from SIEBERS (1999) } \\
& \mathrm{A}_{0}=\text { Section area of the injection orifice, } \mathrm{m}^{2} \\
& \mathrm{aTDC}=\text { After top dead center } \\
& \mathrm{b}=\text { Empirical constant, } 0.41 \text { from SIEBERS (1999) } \\
& \mathrm{B}=\text { Thermodynamic balance } \\
& \mathrm{C}=\text { Empirical constant dependent on ignition-delay } \\
& \quad \text { characteristics of fuel } \\
& \mathrm{CA}=\text { Crankshaft angle, degrees } \\
& \mathrm{C}_{\mathrm{A}}=\text { Coefficient of area-contraction of the injection orifice } \\
& \mathrm{C}_{\mathrm{BS}}=\text { Base soot formation constant }
\end{aligned}
$$

Paper accepted June, 2005. Technical Editor: Atila P. Silva Freire.
$\mathrm{C}_{\mathrm{D}}=$ Discharge coefficient of the injection orifice

$\mathrm{C}_{\mathrm{P}}=$ Specific heat, $\mathrm{kJ} /(\mathrm{kg} \mathrm{K})$

$\mathrm{C}_{\mathrm{SO}}=$ Soot oxidation constant

$\mathrm{C}_{\mathrm{V}}=$ Velocity coefficient of the injection orifice

$\mathrm{D}_{\mathrm{T}}=$ Thermal diffusivity of the air-fuel mixture, $\mathrm{m}^{2} / \mathrm{s}$

$\mathrm{d}=$ Physical diameter of the orifice, $\mathrm{m}$

$\mathrm{d}_{\mathrm{f}}=$ Effective diameter of the orifice, $\mathrm{m}$

$\mathrm{E}_{\mathrm{R}}=$ Energy released in the cylinder, $\mathrm{MJ} / \mathrm{s}$

$\mathrm{E}=$ Activation energy, $\mathrm{cal} / \mathrm{mol}$

$\mathrm{H}=$ Total energy of products or reactants, $\mathrm{kJ}$

$\mathrm{h}=$ Enthalpy, $\mathrm{kJ} / \mathrm{kg}$

$\boldsymbol{h}_{\boldsymbol{x}}^{0}=$ Heat of formation of species, $\mathrm{kJ} / \mathrm{kg}$

$\mathrm{HF}_{\text {meas }}=$ Measured volume of ISO 4113 oil in the standard discharge coefficient test, $\mathrm{cm}^{3}$

$l_{n}=$ Length of the injector orifice, $m$

$\mathrm{L}^{+}=$Dimensionless liquid length

$\mathrm{LHV}=$ Lower heating value of the fuel, $\mathrm{MJ} / \mathrm{kg}$

$\mathrm{L}=$ Liquid length, $\mathrm{mm}$

$\mathrm{LO}=$ Lift-Off length, mm

$\mathrm{M}=$ Molar mass, $\mathrm{kg} / \mathrm{kmol}$

$\mathrm{m}_{\mathrm{A}}=$ Mass of fuel available in soot cloud, $\mathrm{kg}$

$\mathrm{m}_{\mathrm{I}}=$ Mass of fuel injected, $\mathrm{kg}$

$\mathrm{m}_{\mathrm{s}}=$ Mass of particulate, $\mathrm{kg}$

$\mathrm{n}_{\text {orifices }}=$ Number of injection orifices on injector

$\mathrm{P}=$ Cylinder pressure, $\mathrm{MPa}$

$\mathrm{R}=$ Universal gas constant

$\mathrm{R}_{1}=$ Ratio of mass of oxygen to mass of fuel for stoichiometric mix

$\mathrm{R}_{2}=$ Ratio of mass of fuel on fuel stream (normally 1 for pure fuels)

$\mathrm{R}_{3}=$ Ratio of mass of oxygen in the oxidizer stream (0.232 is used for air; PETERS, 2000)

$\mathrm{Re}_{\mathrm{L}}=$ Reynolds number of the liquid flow

$\mathrm{S}_{\mathrm{L}(\mathrm{st})}=$ Laminar flame speed of the stoichiometric mix, $\mathrm{m} / \mathrm{s}$

$\mathrm{T}=$ Temperature, $\mathrm{K}$

$\mathrm{U}_{0}=$ Injection velocity of the fuel, $\mathrm{m} / \mathrm{s}$

$\mathrm{We}_{\mathrm{L}}=$ Weber number of the liquid flow

$\mathrm{x}^{+}=$Length scale, $\mathrm{mm}$

$\mathrm{Y}_{\mathrm{O} 2}=$ Molar fraction of oxygen present

$\mathrm{Z}_{\mathrm{st}}=$ Stoichiometric-fuel-mixture fraction

\section{Greek Symbols}

$\Delta \mathrm{P}_{1}=$ Pressure drop through the injector nozzle, $\mathrm{Pa}$

$\varepsilon=$ Compressibility factor

$\theta=$ Spray angle 
$\lambda=$ Thermal conductivity, $\mathrm{W} /(\mathrm{m} \mathrm{K})$

$\rho=$ Density, $\mathrm{kg} / \mathrm{m}^{3}$

$\phi=$ Equivalence ratio

\section{Subscripts}

a - Relative to air

$\mathrm{f}$ - Relative to fuel

sf - Relative to soot formation

so - Relative to soot oxidation

1 - Relative to initial condition

2 - Relative to thermodynamic equilibrium

\section{Conceptual Model}

The fuel is injected into the combustion chamber slightly before the desired time of combustion, as the piston reaches the end of the compression stroke. The liquid fuel atomizes into small droplets, evaporates and mixes with the hot and compressed air of the combustion chamber. Because the air temperature and pressure are above the fuel's ignition point, spontaneous ignition occurs after a short delay. The time interval between the start of injection and the first heat release is called the ignition delay. After the ignition delay period, the subsequent Diesel combustion process is commonly divided into two stages. During the initial phase the fuel which has mixed with air to within the flammability limits combusts rapidly. This phase of the combustion process is commonly referred to as premixed phase and is associated with high rates of heat release over a few crank angle degrees. The combustion heat-release history during this interval depends strongly on the fuel-air mixture prepared during the ignition delay period.

DEC (1997), describes the formation and features of a quasisteady diesel fuel jet, as shown in Fig. 1. It should be noted that this conceptual model applies to large bore, quiescent chamber combustion or a free fuel jet without wall interactions.

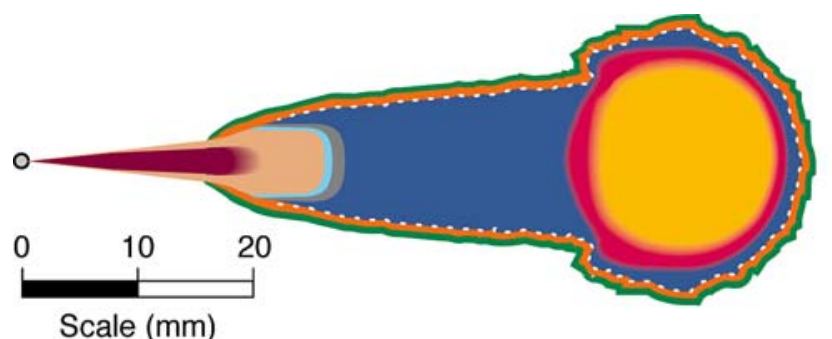

Scale $(\mathrm{mm})$

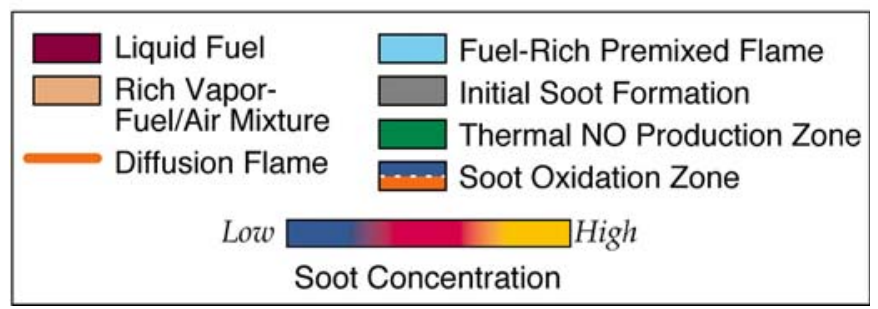

Figure 1. Quasi-steady Diesel combustion plume as presented by DEC (1997). Courtesy Dr. John E. Dec (Sandia National Laboratories).

At the start of injection, fuel begins to penetrate into the combustion chamber and high temperature air is entrained into the spray. The hot air evaporates the fuel and beyond a fixed length, knows as the liquid length, no liquid fuel exists. The liquid length shortens slightly after the start of combustion but remains relatively constant until the end of injection. Beyond the liquid length, the rich premixed fuel and air continue to be heated until they react in the rich premixed reaction zone. The products of rich combustion continue downstream and diffuse and mix radially outward until reaching the surrounding cylinder gases. At a location where the rich products and cylinder gases mix to produce a stoichiometric mixture, a diffusion flame is produced. The diffusion flame surrounds the jet in a thin turbulent sheet, which extends upstream toward the nozzle. The axial distance from the nozzle exit to the diffusion flame is the Lift-Off length. According to SIEBERS \& HIGGINS (2001) the Lift-Off length. controls the amount of oxygen entrained into the fuel jet and therefore the stoichiometry of the fuelrich zone. Soot is burned out and $\mathrm{NO}_{\mathrm{X}}$ is produced on the outside of the diffusion flame, where temperatures are high and oxygen and nitrogen are abundant.

Initial pyrolysis of fuel usually identifies a very rich combustion region. The products of this initial pyrolysis have abundant amounts of soot precursors, like $\mathrm{C}_{2} \mathrm{H}_{2}, \mathrm{C}_{2} \mathrm{H}_{4}$, and the radical $\mathrm{C}_{3} \mathrm{H}_{3}$, for seed particles, as well as unburned hydrocarbons, for growth species. Initial soot particles form and grow in size through agglomeration, direct deposit, and surface growth. The soot particles, soot precursors and growth species, are all oxidized as they mix with surrounding air at high temperatures. The initial pyrolysis of the fuel occurs at the rich initial reaction that exists just downstream of the liquid length. Furthermore, just downstream of this reaction, observations from DEC (1997) have shown the existence of a zone where small soot particles begin to form. The particles take root and grow as they move down the turbulent fuel jet toward the head vortex. Oxidation of the soot particles occurs when they pass close to, or through the diffusion flame formed around the periphery of the spray plume, where the particles are exposed to oxygen.

SIEBERS \& HIGGINS (2001) found the equivalence ratio of the rich initial reaction was dependent on the Lift-Off length. The only oxygen for the initial reaction comes from the air entrained in the fuel spray; the diffusion flame sheath prevents further entrainment. A larger Lift-Off length allows more air entrainment and a lower equivalence ratio for the initial reaction. Lower equivalence ratios for the reaction, would result in fewer unburned hydrocarbons in the products. A vast majority of the soot particles formed during the Diesel combustion are oxidized before the combustion event is quenched (HEYWOOD, 1988). In the final stage of the combustion event a "race" occurs between the dropping temperature due the expansion cooling and the rate of the soot oxidation. The particulate matter left when the final stage of combustion is quenched, becomes the soot expunged from the cylinder and into the exhaust of the engine.

\section{Spray Model}

\section{Injection Coefficients}

To characterize mass and momentum fluxes of fuel leaving the orifice, two of three coefficients for the injector tip are required (NABER \& SIEBERS, 1996): the discharge coefficient $\left(C_{D}\right)$, the velocity coefficient $\left(\mathrm{C}_{V}\right)$, and the area contraction coefficient $\left(\mathrm{C}_{\mathrm{A}}\right)$. The discharge coefficient characterizes the mass flux from an orifice, while the area contraction or velocity coefficients allow the momentum flux to be characterized as well. The area contraction coefficient accounts for flow area loss as result of vapor bubbles generated by cavitation. The three coefficients are related by the Eq. (1). The more common situation in the literature however, is that only a discharge coefficient is available. At higher injection pressures, assuming a $\mathrm{C}_{\mathrm{V}}$ of one, would only result in a few percent over estimated of the momentum flux (SIEBERS, 1999).

$$
C_{D}=C_{A} \cdot C_{V} .
$$


The discharge coefficient of the orifices could be determined by a standard test, with the prescribed calibrating oil defined by ISO standard 4113 , in the fixed temperature of $40^{\circ} \mathrm{C}$. In the test, with a nozzle holder without the pressure pin and under a pressure drop of $400 \mathrm{bar}$, the delivered oil volume in $\mathrm{cm}^{3}$ is measured in a glass gage for 60 seconds. It is possible to calculate the discharge coefficient from the measured volume by the Eq. (2), derived from Bernoulli's equation (ARGACHOY, 2001), where $\rho_{\text {ISO }} 4113$ is the density of the ISO 4113 oil in $40{ }^{\circ} \mathrm{C}\left(\sim 807 \mathrm{~kg} / \mathrm{m}^{3}\right), \mathbf{H F}_{\text {meas }}$ is the measured volume $\left(\mathrm{cm}^{3}\right), \boldsymbol{n}_{\text {orifices }}$ is the number of injection orifices on injector, $\boldsymbol{A}_{0}$ is the section area of each orifice $\left(\mathrm{m}^{2}\right)$, and $\Delta \boldsymbol{P}_{\boldsymbol{I}}$ is the pressure drop through the injector.

$$
C_{D}=\frac{\rho_{\text {ISO } 4113}\left(\frac{H F_{\text {meas }}}{n_{\text {orifices }}}\right)}{6.10^{7}\left(A_{0} \sqrt{2 \rho_{\text {ISO } 4113 \Delta P_{l}}}\right)} .
$$

\section{Spray Angle}

When a liquid is injected, under pressure, into a volume of gas, the liquid breaks apart into a spray of droplets that eventually vaporize. Geometry of the injector orifice and the ratio of densities of the gas and liquid will determine the angle developed by the spray. A wider spray angle would result in a larger mass of gas being entrained as the liquid jet moves away from the nozzle. The model of REITZ \& BRACCO (1979) for the spray angle $(\theta)$ in Eq. (3) and (4), uses the aspect ratio of the nozzle, where the aspect ratio refers to the length-to-diameter ratio of the orifice $\left(l_{n} / d\right)$, as well as the ratio of air and fuel densities $\left(\rho_{\mathrm{a}} / \rho_{\mathrm{f}}\right)$ and the ratio of the Reynolds and Weber numbers of the fuel flow $\left(\mathrm{Re}_{\mathrm{f}} / \mathrm{We}_{\mathrm{f}}\right)$. The function $f$ is a constant with the value of $\sqrt{3} / 6$.

$$
\begin{gathered}
\tan (\theta / 2)=\frac{1}{A} \cdot 4 \pi \cdot\left(\frac{\rho_{a}}{\rho_{f}}\right)^{1 / 2} \cdot f\left(\frac{\rho_{f}}{\rho_{a}} \cdot \frac{\mathrm{Re}_{f}}{W e_{f}}\right)^{2} . \\
\boldsymbol{A}=3.0+(0.28) \cdot\left(\frac{\boldsymbol{I}_{\boldsymbol{n}}}{\boldsymbol{d}}\right) .
\end{gathered}
$$

Equation (3) simplifies into Eq. (5) for an injector which the spray atomizes at injector nozzle (HEYWOOD, 1988). Most modern Diesel injectors operate at sufficient pressures to cause atomization at the nozzle.

$$
\tan (\theta / 2)=\frac{1}{A} \cdot 4 \pi \cdot\left(\frac{\rho_{a}}{\rho_{f}}\right)^{1 / 2} \cdot \frac{\sqrt{3}}{6}
$$

\section{Liquid Length}

The distance penetrated by the fuel before vaporization is known as the liquid length. SIEBERS (1999) developed a scaling law to predict the liquid length. The scaling law is based on the idealized spray model shown in Fig. 2.

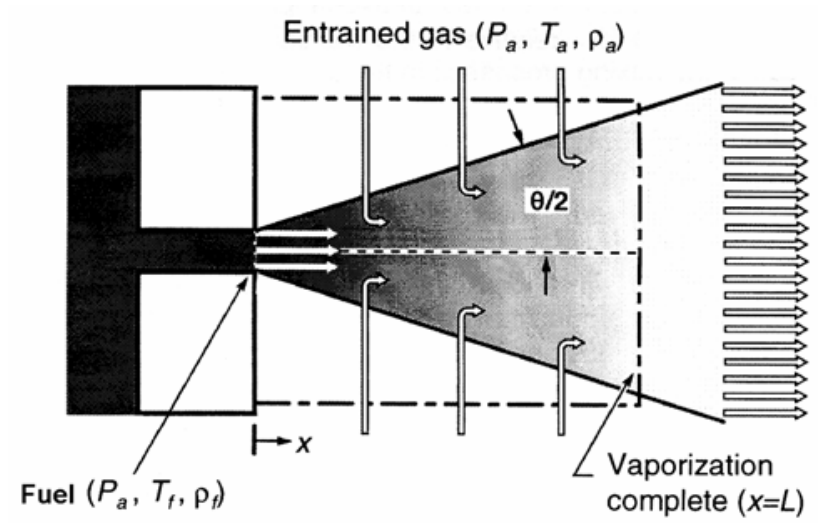

Figure 2. Spray vaporization model from SIEBERS (1999).

The assumptions made by SIEBERS (1999), applies in his model, include quasi-steady flow with a uniform rate, uniform velocity, uniform fuel concentration and uniform temperature profiles (i.e., perfect mixing inside the spray boundaries), and finally no velocity slip between the injected fuel and the entrained gas. The no velocity slip assumption is doubtful very near the injector orifice, but should begin applying well before the axial location of complete vaporization. From the instant the liquid jet leaves the nozzle, it begins to entrain the surrounding gas at a constant rate, thus the conical spray angle. Consequently, the mass of gas entrained is directly proportional to the distance from the nozzle. SIEBERS \& HIGGINS (2001) developed a length scale $\left(\boldsymbol{x}^{+}\right)$found in Eq. (6), that normalizes injection lengths permitting dimensionless quantities to characterize aspects of the injecting spray, where $\left(\rho_{\mathrm{f}} / \rho_{\mathrm{a}}\right)$ is the ratio of fuel and gas densities, the letter $a$ is a empirical constant (0.66), and $\theta$ is the spray angle.

$$
x^{+}=\sqrt{\frac{\rho_{f}}{\rho_{a}}} \cdot \frac{d_{f}}{a \cdot \tan (\theta / 2)} .
$$

The effective diameter of the orifice $\left(\mathrm{d}_{\mathrm{f}}\right)$ represents the reduction of useful area when flow through the orifice becomes choked. Eq. (7) demonstrates how the effective area can be found, where $C_{A}$ is the coefficient of area contraction and $\mathrm{d}$ is the physical diameter of the orifice.

$$
d_{f}=\sqrt{C_{A}} \cdot d
$$

The equation (8) shows the liquid length $\left(L^{+}\right)$expression based on SIEBERS (1999). The actual liquid length is determined by multiplying the dimensionless liquid length by the length scale of the liquid spray. In Eq. (8), b is an empirical constant (0.41), and B is obtained by a thermodynamic balance.

$$
L^{+}=b \cdot \sqrt{\left(\frac{2}{B}+1\right)^{2}-1} .
$$

The liquid length relation depends on the ratio of mass flows of air and fuel represented by the term B, which itself is a balance of two thermodynamic relations (SIEBERS, 1999). The Eq. (9) shows these relations. 


$$
B=\frac{\varepsilon_{a}\left(T_{2}, P_{a 2}\right) \cdot P_{f 2} \cdot M_{f}}{\varepsilon_{f}\left(T_{2}, P_{f 2}\right) \cdot P_{a 2} \cdot M_{a}}=\frac{h_{a 1}-h_{a 2}}{h_{f 2}-h_{f 1}} .
$$

Where $\varepsilon_{\mathrm{a}}$ is the compressibility of air at the conditions of $\mathrm{T}_{2}$ and $\mathrm{P}_{\mathrm{a} 2}, \varepsilon_{\mathrm{f}}$ is the compressibility of the vaporized fuel at the conditions $\mathrm{T}_{2}$ and $\mathrm{P}_{\mathrm{f} 2} ; \mathrm{P}_{\mathrm{a} 2}$ is the partial pressure of air at thermodynamic equilibrium, $\mathrm{P}_{\mathrm{f} 2}$ is the partial pressure of the fuel at thermodynamic equilibrium, $\mathrm{T}_{2}$ is the temperature reached by the fuel and air at thermodynamic equilibrium, $\mathrm{M}_{\mathrm{f}}$ is the molar mass of the fuel, $\mathrm{M}_{\mathrm{a}}$ is the molar mass of air, $h_{a 1}$ is the initial enthalpy of the entrained air, $\mathrm{h}_{\mathrm{a} 2}$ is the final enthalpy of the entrained air at thermodynamic equilibrium, $h_{f 1}$ is the initial enthalpy of the fuel, and $h_{f 2}$ is the final enthalpy of the fuel at thermodynamic equilibrium.

Restricting the final state of the fuel to saturated vapor and assuming the final mix of fuel and air to be in thermodynamic equilibrium, allows an iterative approach to finding the final temperature of the air-fuel mixture. After an initial guess for $T_{2}$ is made, the vapor pressure of the fuel can be found, as well as can the other properties of the vaporized fuel in the hypothesized thermodynamic state. The partial pressure of the air can be found by subtracting the partial pressure of the fuel from the total cylinder pressure, at the guessed temperature $\mathrm{T}_{2}$. At that point, it is possible to determine all the other properties of the air at the chosen state. If the two halves of Eq. (9) are not equal, a new guess is made, utilizing a binary search with a continually narrowing search area.

\section{Lift-Off Length}

The Lift-Off length (LO) is the distance from the injector to the point along the Diesel spray where the diffusion flame sheaths the spray and the air can no longer be entrained into the spray. The LiftOff length, although coupled to the liquid length, also depends strongly on the thermodynamic and reactive properties of the fuel. The relation that calculates the Lift-Off, set in Eq. (10), is based on the expression of SIEBERS apud BAYER \& FOSTER (2003).

$$
L O=(0.25) \cdot L+C \cdot\left(\frac{U_{0} \cdot Z_{s t} \cdot D_{T}}{S_{L(s t)}^{2} \cdot \tan (\theta / 2)}\right) \text {. }
$$

Where $\mathrm{L}$ is the liquid length, $\mathrm{U}_{0}$ is the injection velocity of the fuel, $\mathrm{Z}_{\mathrm{st}}$ is the stoichiometric fuel mixture fraction, $\mathrm{D}_{\mathrm{T}}$ is the thermal diffusivity of the air-fuel mixture, $\mathrm{S}_{\mathrm{L}(\mathrm{st})}$ is the laminar flame speed of the stoichiometric mix, $\mathrm{C}$ is an empirical constant, dependent on ignition delay characteristics of fuel, with a value of 3.5 , and tan $(\theta / 2)$ is the tangent of the spray half angle. The value of the stoichiometric fuel mixture fraction $\left(\mathrm{Z}_{\mathrm{st}}\right)$ is defined by PETERS (2000) in the Eq. (11), where $R_{1}$ is the ratio of mass of oxygen to mass of fuel for stoichiometric mix, $R_{2}$ is the ratio of mass of fuel on fuel stream (normally 1 for pure fuels), and $R_{3}$ is the ratio of mass of oxygen in the oxidizer stream ( 0.232 is used for air). This fraction $\left(Z_{s t}\right)$ remains constant for a given fuel.

$$
Z_{s t}=\left(1+\frac{R_{1} \cdot R_{2}}{R_{3}}\right)^{-1}
$$

Thermal diffusivity $\left(\mathrm{D}_{\mathrm{T}}\right)$ is defined also by PETERS (2000) in Eq. (12), as an indicator of how quickly the heat of reaction is passed downstream, to heat the incoming reactants to a temperature appropriate to propagate the reaction.

$$
D_{T}=\frac{\lambda}{\rho \cdot C_{p}} \text {. }
$$

Where $\lambda$ is the thermal conductivity of the material, $\rho$ is the density of the material, and $C_{p}$ is the specific heat of the material. The laminar flame speed for the stoichiometric mixture of air and fuel $\left(\mathrm{S}_{\mathrm{L} \text { (st) }}\right)$ in $\mathrm{m} / \mathrm{s}$ is calculated from the temperature of mixture in $K\left(T_{u}\right)$ and the pressure of the mixture in bar $(P)$, using the empirical relation expressed in Eq. (13). The relation was developed by BRADLEY et al. (1998), from measurements taken of a $10 \% \mathrm{n}$ heptane and $90 \%$ iso-octane mixture, but was found to be useful for similar hydrocarbon fuels.

$$
S_{L(s t)}=0.48 \cdot\left(\frac{T_{u}}{358}\right)^{1.01} \cdot P^{-0.282} .
$$

\section{Equivalence Ratio}

The equivalence ratio of the initial reaction $(\phi)$ can be determined from the Lift-Off length (LO). Under the assumption of an ideal spray model, the mass of air entrained into the fuel spray is a function of the distance from the injector tip. SIEBERS \& HIGGINS (2001) developed the Eq. (14) for the equivalence ratio, during their investigation of Lift-Off length, where $\boldsymbol{x}^{+}$is the characteristic length scale. Assuming no air can be entrained once the spray is sheathed in the diffusion flame, the Lift-Off length becomes the determining factor for the maximal mass of air entrained.

$$
\phi=\frac{100}{\frac{10}{3} \cdot\left(\sqrt{1+16 \cdot\left(\frac{L O}{x^{+}}\right)^{2}}-1\right)} .
$$

\section{Soot Model}

The soot model is based on modified versions of rate equations developed by HIROYASU \& KADOTA (1976) for soot formation and soot oxidation. The Eq. (15) shows the net soot rate formula used (PATTERSON et al., 1994).

$$
\dot{m}_{s}=\dot{m}_{s f}-\dot{m}_{s o} .
$$

Where $\dot{m}_{s}$ is the net mass rate of soot formation, $\dot{\boldsymbol{m}}_{\boldsymbol{s f}}$ is the mass rate of soot formation, and $\dot{\boldsymbol{m}}_{\boldsymbol{s o}}$ is the mass rate of soot oxidation. The net mass rate of soot formation is integrated with respect to time over the combustion event, to determine the total mass of soot at any moment in the cylinder. Based on the work of KAZAKOV \& FOSTER (1998), once quenching conditions are met, mainly temperature of formation drops below $1000 \mathrm{~K}$, soot calculations end, and the model is immediately reset for the next combustion event.

\section{Soot Formation}

KHAN \& GREEVES (1974) indications are, that under high temperature and short reaction time conditions, encountered in a Diesel combustion chamber, the overall mechanism of soot formation may be characterized by an Arrhenius type equation. Equation (16), based on the expression of PATTERSON et al. 
(1994), defines the soot formation rate $\left(d m_{s f} / d t\right)$, where $C_{\mathrm{BS}}$ is the base soot formation constant, $\phi$ is the equivalence ratio of the initial reaction, $\mathrm{m}_{\mathrm{f}}$ is the mass of fuel available to soot reaction, $\mathrm{P}$ is the cylinder pressure, $E_{\mathrm{sf}}$ is the activation energy of the soot formation reaction $(12500 \mathrm{cal} / \mathrm{mol}), \mathrm{R}$ is the universal gas constant (1.9872 cal/gmol K), and $\mathrm{T}$ is the temperature in the soot formation region.

$$
\frac{d m_{s f}}{d t}=C_{B S} \cdot \phi \cdot m_{f} \cdot P^{0.5} \cdot \exp \left(-E_{s f} / R \cdot T\right)
$$

The empirical base soot formation constant adapts the model to a specific engine and fuel type. The temperature in the sootformation region is determined by first establishing the temperature of the rich reaction products and how they are affected by the diffusion flame and pressure. To establish the temperature rise due to the rich reaction, a simplified one-way reaction is utilized (TURNS, 1996). The heats of formation and mass fractions are used in Eq. 17 through 19 to determine the temperature of the products. Reactants are n-heptane, used as a single component fuel to simulate Diesel, and air, taken to be an oxygen and nitrogen mix. Reaction products for an ideal reaction are assumed to be carbon dioxide, carbon monoxide, water, excess fuel (f2) and nitrogen. The equivalence ratio $(\phi)$ is determined from the spray model, and the mass fractions of products are interpolate, from tabulated data of STANJAN (Chemical Equilibrium Solver, v 3.96 - Stanford University, 1995), for different equivalence ratios.

$$
\begin{gathered}
H_{R}=m_{f}\left(h_{f}^{0}+T_{i n i} \cdot C_{p f}\right)+m_{\mathrm{O}_{2}} \cdot T_{i n i} \cdot C_{p \mathrm{O}_{2}}+m_{N_{2}} \cdot T_{i n i} \cdot C_{p_{N_{2}}} \cdot(17) \\
H_{P}=m_{C Q_{2}}\left(h_{C Q_{2}}^{0}+T_{f i n} \cdot C_{p C Q}\right)+m_{C O} \cdot\left(h_{C O}^{0}+T_{f i n} \cdot C_{p_{C O}}\right)+m_{N_{2}} \cdot T_{f i n} \cdot C_{p_{N_{2}}}+ \\
m_{\mathrm{H}_{2} \mathrm{O}}\left(h_{\mathrm{H}_{2} \mathrm{O}}^{0}+T_{f i n} \cdot C_{p_{\mathrm{H}_{2} \mathrm{O}}}\right)+m_{f_{2}}\left(h_{f}^{0}+T_{f i n} \cdot C_{P_{f}}\right) . \\
H_{R}=H_{P} .
\end{gathered}
$$

Where $\mathrm{m}_{\mathrm{x}}$ is the mass fraction of species $\mathrm{x}, h_{x}^{0}$ is the heat of formation of species, $C p_{x}$ is the specific heat of species, $T_{i n i}$ is the initial temperature of reactants, $T_{\text {fin }}$ is the final temperature of products, $H_{R}$ is the total energy of reactants, and $H_{P}$ is the total energy of products.

Soot can only be formed when unburned fuel is available in the soot formation cloud. To determine the mass of fuel that is unburned and thus available to form soot, a simple thermodynamic relation based on the mass conservation is performed in Eq. (20).

$$
\dot{m}_{A}=\dot{m}_{I}-\frac{E_{R}}{L H V_{f}} .
$$

Where $\dot{m}_{A}$ is the mass flow of fuel available in soot cloud, $\dot{m}_{I}$ is the mass flow of fuel injected, $E_{\mathrm{R}}$ is the energy released in the cylinder, and the $\mathrm{LHV}_{\mathrm{f}}$ is the lower heating value of the fuel. The mass of fuel injected into the cylinder is determined by integrating the mass flow of fuel during injection with respect to time. The energy released is found by integrating the heat release rate of the combustion event with respect to time.

\section{Soot Oxidation}

Equation (21) is an Arrhenius rate equation for soot oxidation, based on the work of PATTERSON et al. (1994). Where $d m_{s o} / d t$ is the rate of soot oxidation, $\mathrm{C}_{\mathrm{SO}}$ is the soot oxidation constant, $\mathrm{m}_{\mathrm{s}}$ is the mass of soot, $\mathrm{Y}_{\mathrm{O} 2}$ is the molar fraction of oxygen present, $\mathrm{P}$ is the cylinder pressure, $\mathrm{E}_{\mathrm{so}}$ is the activation energy of the soot oxidation reaction $(14000 \mathrm{cal} / \mathrm{mol}), \mathrm{R}$ is the universal gas constant (1.9872 cal/gmol K), and $\mathrm{T}$ is the temperature in the soot oxidation region.

$$
\frac{d m_{s O}}{d t}=C_{S O} \cdot m_{s} \cdot Y_{O_{2}} \cdot P^{1.8} \cdot \exp \left(-E_{\text {SO }} / R \cdot T\right) .
$$

The base soot oxidation constant is, once again, empirically determined to adapt the oxidation rate to a specific engine and fuel type. Soot oxidation occurs in and around the diffusion flame. The diffusion flame is the area where a turbulent flame front has developed from the mixing of fresh air, with incompletely reacted products of the rich initial reactions. This turbulent flame front is often considered to be occurring near a stoichiometric condition (DEC, 1997). Thus, the molar fraction of oxygen in the region of oxidation is assumed to be equal the molar fraction of oxygen on the reactant side of a stoichiometric mixture of air and n-heptane. The temperature of the soot oxidation region is established in a similar way to that used for the soot formation region. However, the simplified reaction is assumed to occur at an equivalence ratio of 1 , to simulate the stoichiometric conditions assumed in the diffusion flame (DEC, 1997). Eq. 17 through 19 again predict the temperature of the combustion products. The temperature of the reactants is assumed to be that of the soot formation region, until all of the fuel in the soot formation is burned.

\section{Model Validation}

The model was compared to experimental data to determine the validity of predictions made. The experimental data used for the comparisons was obtained from two sources:

- A research single-cylinder Diesel engine from the work of KWEON et al. (2002), adapted from an in-line six-cylinder 14 liters engine, at the Engine Research Center of the University of Wisconsin-Madison (USA).

- A vehicular six-cylinder, 12 liters, Diesel engine, at the DaimlerChrysler Technological Development Center in Brazil.

\section{Single Cylinder Research Engine}

The specification of the single-cylinder engine employed in the experiments of KWEON et al. (2002) is given in Table 1 . Table 2 displays run conditions for six soot mass measurements of CARB 8 mode emissions test of KWEON et al. (2002). The six data set were generously provided by Prof. Dr. David E. Foster, of the University of Wisconsin-Madison (USA), for model comparisons. The cylinder pressure signal of the low load points, corresponding to points number 4 (25\% load, peak torque speed) and 8 (10\% load, idle speed) was deteriorated, and the particulate mass of these points were not predicted by the model. 
Table 1. The research single-cylinder engine specification (KWEON et al., 2002).

\begin{tabular}{|l|l|}
\hline Engine model & Cummins N14 single cylinder \\
\hline Type & Diesel, direct injection, 4 stroke \\
Combustion chamber & Quiescent \\
Combustion chamber diameter & $97.8 \mathrm{~mm}$ \\
Number of intake valves & 2 \\
Number of exhaust valves & 2 \\
Injection system & Electronic, Unit Injector (UIS) \\
Displacement & $2.333 \mathrm{dm}^{3}$ \\
Bore/Stroke & $139.7 \mathrm{~mm} / 152.4 \mathrm{~mm}$ \\
Connecting rod length & $304.8 \mathrm{~mm}$ \\
Number of nozzle orifices & 8 \\
Nozzle orifices diameter & $0.200 \mathrm{~mm}$ \\
Discharge coefficient of the orifices & 0.86 \\
Aspect ratio of the orifices & 4.1 (length/diameter of orifices) \\
Temperature of the fuel injected & $305 \mathrm{~K}$ \\
Spray angle & $152^{\circ}$ \\
Compression ratio & 13.1 \\
\hline
\end{tabular}

Table 2. Summary of operating conditions of CARB test cycle (KWEON et al., 2002).

\begin{tabular}{|c|c|c|c|c|c|c|}
\hline CARB mode & 1 & 2 & 3 & 5 & 6 & 7 \\
\hline Speed $\left(\mathrm{min}^{-1}\right)$ & 1800 & 1800 & 1800 & 1200 & 1200 & 1200 \\
\hline Load (\%) & 100 & 75 & 50 & 100 & 75 & 50 \\
\hline $\begin{array}{l}\text { Intake pressure } \\
\text { (kPa) }\end{array}$ & 179.3 & 179.3 & 179.3 & 175.2 & 179.3 & 177.9 \\
\hline $\begin{array}{l}\text { Intake } \\
\text { temperature }\left({ }^{\circ} \mathrm{C}\right)\end{array}$ & 49.0 & 48.3 & 48.3 & 48.3 & 49.0 & 48.1 \\
\hline Equivalence ratio & 0.69 & 0.50 & 0.34 & 0.82 & 0.69 & 0.41 \\
\hline $\begin{array}{l}\text { Indicated specific } \\
\text { fuel consumption } \\
\text { (kg/ihp-h) }\end{array}$ & 0.172 & 0.146 & 0.140 & 0.168 & 0.160 & 0.141 \\
\hline $\begin{array}{l}\text { Indicated mean } \\
\text { effective pressure } \\
\text { (MPa) }\end{array}$ & 1.083 & 0.922 & 0.671 & 1.491 & 1.225 & 0.878 \\
\hline $\begin{array}{l}\text { Start of injection } \\
\text { (CA aTDC) }\end{array}$ & -5 & -5 & -5 & -11 & -2 & -2 \\
\hline $\begin{array}{l}\text { Injection duration } \\
\text { (CA) }\end{array}$ & 25 & 20 & 13 & 27 & 22 & 15 \\
\hline
\end{tabular}

When the model detected the end of each combustion cycle during continuous operation of the engine, the conditions in cylinder were reset for the next cycle to begin. The final mass of soot in cylinder, when quenching conditions are reached, was considered soot emitted from the cylinder into the exhaust. Figure 3 shows an example, for the mode 7 of KWEON et al. (2002) data, of the predicted time-history of the soot mass in the combustion chamber. The same analysis was made for the other test modes.

Prediction of particulate matter that exists at the end of the combustion cycle is ultimately the goal of this modeling project. A single data point (mode 7) is chosen as the adapting point for the six operating conditions simulated from KWEON et al. (2002). Figure 4 shows the comparison of the measured soot-mass per fuel mass (KWEON et al., 2002) to the predicted soot-mass per fuel mass. From the studies of McMILLIAN (2002) apud GAUTAM et al. (2004), the uncertainty associated with particulate material measurements using the mini-dilution tunnel varies between $2.8 \%$ to $10 \%$ of the reading. The value of $10 \%$ total uncertainty was chosen for the analyses. Although predicted values do not perfectly match measured values, there is certainly reasonable agreement. Qualitative predictions of the model are valid.

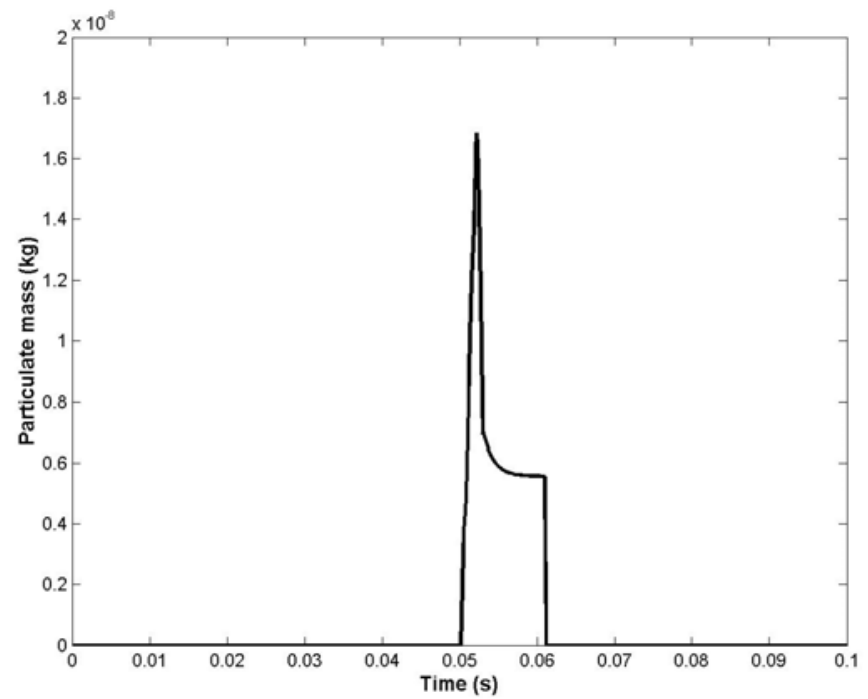

Figure 3. Predicted time-history of the soot mass for the mode 7 of KWEON et al. (2002).

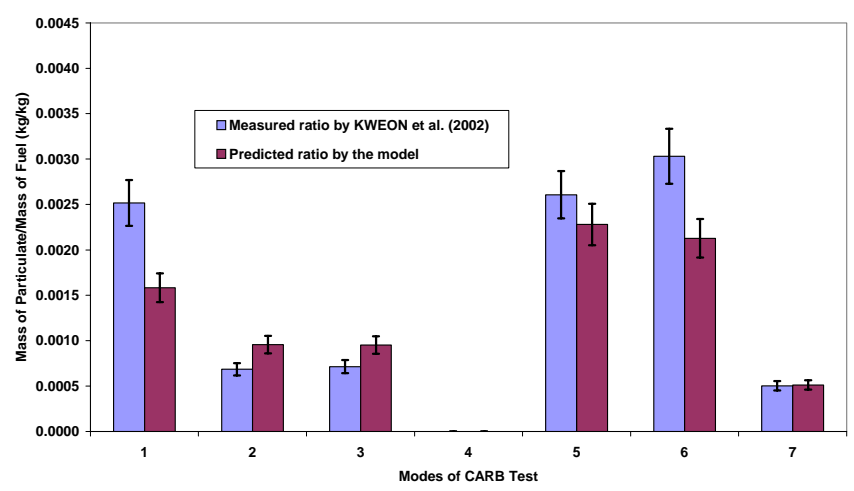

Figure 4. Predicted values by the model versus measured values by KWEON et al. (2002) of particulate mass per mass of fuel.

\section{Six Cylinder Vehicular Engine}

The new model is tested to determine the validity of predictions also for a complete vehicular engine on test bench. The specification of the six-cylinder engine employed in the experiments is given in Table 3, and the engine on the DaimlerChrysler-Brazil test bench can be seen in Fig. 5. Table 4 lists the conditions of the EURO III (ESC - European Stationary Cycle) at which the engine was operating when measurements of soot mass were taken. The engine was equipped with a cylinder pressure transducer (0-20 MPa), and an injection pressure transducer (0-200 MPa), in the sixth cylinder. A needle-motion sensor, also in the sixth cylinder, monitors the start of injection and the injection duration directly at the injection nozzle. The cylinder pressure signal of the low load points $(0 \%$ and $25 \%$ ), corresponding to points number 1 (idle), 7, 9 and 11 was deteriorated, and the particulate mass of these points were not predicted by the model. 


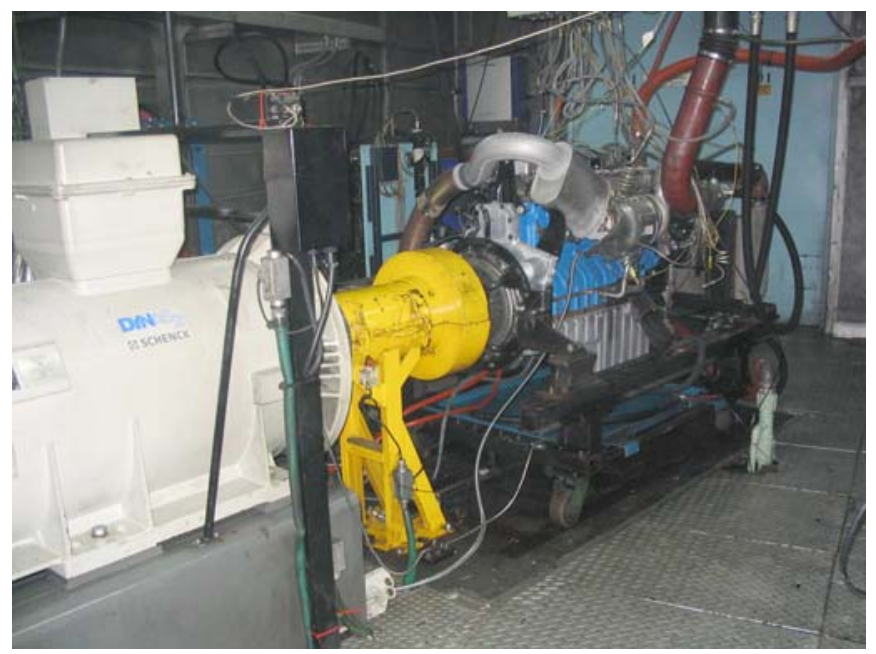

Figure 5. Six cylinder engine on DaimlerChrysler-Brazil test bench.

Table 4. Summary of operating conditions of EURO III test cycle.

\begin{tabular}{|c|c|c|c|c|c|c|c|c|c|}
\hline Points & 2 & 3 & 4 & 5 & 6 & 8 & 10 & 12 & 13 \\
\hline Speed $\left(\min ^{-1}\right)$ & 1135 & 1493 & 1493 & 1135 & 1135 & 1492 & 1876 & 1876 & 1876 \\
\hline Load (\%) & 100 & 50 & 75 & 50 & 75 & 100 & 100 & 75 & 50 \\
\hline Intake pressure (kPa) & 236.2 & 164.9 & 220.4 & 146.9 & 189.2 & 273.5 & 267.1 & 248.9 & 197.6 \\
\hline Intake temperature $\left({ }^{\circ} \mathrm{C}\right)$ & 29.7 & 27.6 & 32.3 & 24.8 & 26.3 & 39.4 & 45.2 & 41.6 & 34.2 \\
\hline Equivalence ratio & 0.67 & 0.40 & 0.45 & 0.50 & 0.60 & 0.51 & 0.47 & 0.39 & 0.32 \\
\hline Mass-flow of fuel (kg/h) & 50.36 & 30.37 & 45.15 & 25.59 & 37.78 & 60.62 & 67.56 & 55.28 & 37.33 \\
\hline Measurement time in each point (s) & 72 & 90 & 90 & 45 & 45 & 80 & 72 & 45 & 45 \\
\hline Start of injection (CA aTDC) & -11 & -11 & -10 & -11 & -10 & -13 & -12 & -5 & -5 \\
\hline Injection duration (CA) & 28 & 21 & 29 & 19 & 22 & 35 & 38 & 35 & 30 \\
\hline
\end{tabular}

For the current study, one primary and one secondary particulate filters for each measurement was used, not only a pair of filters for the complete EURO III test. The system used was the AVL SPC 472 Smart Sampler. As an example, Fig. 6 shows the predicted timehistory of the soot mass in the combustion chamber for the point 3 . Comparing the particulate-mass time-history of the engines, it can be seen that the single-cylinder engine has a high peak of soot formation. This characteristic is probably related with the very low compression rate of the adapted single-cylinder engine (13.1:1), in comparison with the vehicular complete engine (17.25:1). Again, a single data point (point 3 ) is chosen as the adapting point for the all other operating conditions simulated. Figure 7 shows the comparison of the measured soot-mass per fuel mass (test bench) to the predicted soot-mass per fuel mass (model). From the work of McMILLIAN (2002) apud GAUTAM et al. (2004), the value of $10 \%$ total uncertainty was chosen for the analyses using minidilution tunnel. Qualitative predictions of the model, are valid also for the six cylinder vehicular engine.

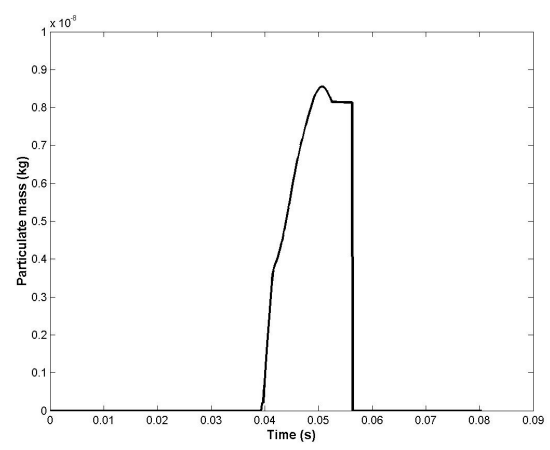

Figure 6. Predicted time-history of the soot mass for the point 3 of the EURO III test.
Table 3. The vehicular engine specification.

\begin{tabular}{|l|l|}
\hline Engine model & Mercedes-Benz OM457LA \\
\hline Type & Diesel, direct injection, 4 stroke \\
Number of cylinders & 6 (in line) \\
Combustion chamber & Quiescent \\
Combustion chamber diameter & $92.8 \mathrm{~mm}$ \\
Number of intake valves & 2 \\
Number of exhaust valves & 2 \\
Injection system & Electronic, Unit Pump (UPS) \\
Total Displacement & $11.967 \mathrm{dm}^{3}$ \\
Bore/Stroke & $128 \mathrm{~mm} / 155 \mathrm{~mm}$ \\
Connecting rod length & $251 \mathrm{~mm}$ \\
Number of nozzle orifices & 6 \\
Nozzle orifices diameter & $0.229 \mathrm{~mm}$ \\
Discharge coefficient of the orifices & 0.72 \\
Aspect ratio of the orifices & 4.4 (length/diameter of orifices) \\
Temperature of the fuel injected & $308 \mathrm{~K}$ \\
Spray angle & $150^{\circ}$ \\
Compression ratio & 17.25 \\
\hline
\end{tabular}

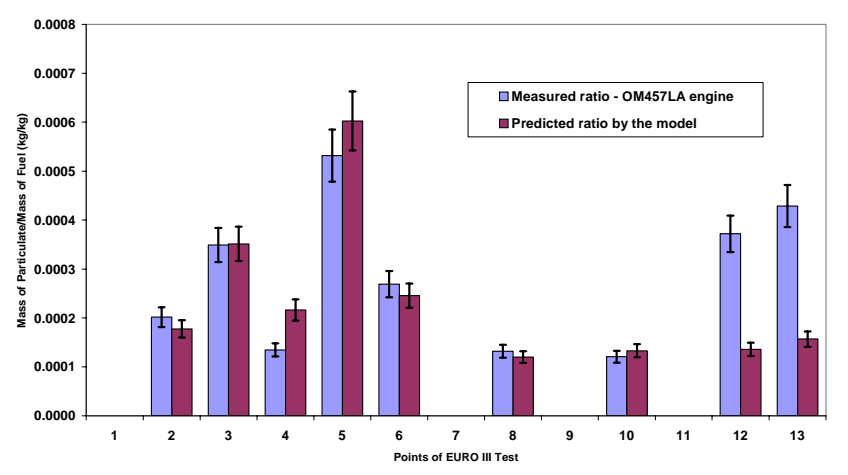

Figure 7. Predicted values by the model versus measured values from DaimlerChrysler-Brazil test bench, of particulate mass per mass of fuel.

\section{Conclusions}

A new phenomenological model has been compared with results from two engines, a single-cylinder research engine and a vehicular six-cylinder engine. The simulation, as shown in above sections, has achieved a reasonable level of fidelity. Qualitative predictions of the model are valid for both, the single-cylinder engine and also the vehicular six-cylinder engine. The model predicts the particulate mass, and also identifies intrinsic differences between the combustion process of the two engines, like the compression ratio. The model also shows a great potential for expansion. A complex chemistry solver could be interfaced at the initial reaction point, to determine a detailed description of exhaust gasses that contribute to particulate emissions. 


\section{Acknowledgments}

The authors would like to thank Prof. Dr. David E. Foster of the University of Wisconsin-Madison (USA) for single-cylinder engine data used in the model comparisons, and Dr. John E. Dec of the Sandia National Laboratories (USA) for information and the picture of Diesel combustion plume. The authors would also like to thank the Department of Heavy Engine Development of DaimlerChryslerBrazil, for the generous support.

\section{References}

Argachoy, C., “Aplicação da Técnica Interferométrica a Laser e do Princípio da Máxima Entropia na Análise de Injetores de Motores Diesel” (In Portuguese), M.Sc. Thesis, ITA, 2001.

Bayer, J., Foster D. E., “Zero-Dimensional Soot Modeling”, SAE Paper 2003-01-1070, 2003.

Bradley, D., Hicks, R. A., Lawes, M., Sheppard, C. G. W., Woolley, R., "The Measurement of Laminar Burning Velocities and Markstein Numbers for Iso-octane-Air and Iso-octane-n-Heptane-Air Mixtures at Elevated Temperatures and Pressures in an Explosion Bomb”, Combustion and Flame 115:126-144, 1998.

Dec, J. E., “A Conceptual Model of DI Diesel Combustion Based on Laser Sheet Imaging”, SAE Paper 970873, 1997.

Gautam, M., Carder, D. K., Thompson, G. J., Clark, N. N., Nayak, G., Krishnamurthy, M., Development of a Test Method to Measure Stationary and Portable Engine Emissions, Project CARB 00-06 by West Virginia University, 2004.
Heywood, J. B., "Internal Combustion Engine Fundamentals”, McGrawHill, 1988.

Hiroyasu, H., Kadota, T., "Models for Combustion and Formation of Nitric Oxide and Soot in Direct Injection Diesel Engines", SAE Paper $760129,1976$.

Kazakov, A., Foster, D. E., "Modeling of Soot Formation During DI Diesel Combustion Using a Multi-Step Phenomenological Model, SAE Paper 982463, 1998.

KHAN, I. M., GREEVES, G., "A Method for Calculating the Formation and Combustion of Soot in Diesel Engines”, In: Heat Transfer in Flames, Afgan, N. H. and Beer, J.M., (Eds.), Scripta, 1974.

Kweon, C. B., Foster, D. E., Schauer, J. J., Okada, S., "Detailed Chemical Composition and Particle Size Assessment of Diesel Engine Exhaust”, SAE Paper 2002-01-2670, 2002.

Naber, J. D., Siebers, D. L., "Effects of Gas Density and Vaporization on Penetration and Dispersion of Diesel Sprays”, SAE Paper 960034, 1996.

Patterson, M. A., Kong, S. C., Hampson, G. J., Reitz, R. D., “Modeling the Effects of Fuel Injection Characteristics on Diesel Engine Soot and $\mathrm{NO}_{\mathrm{X}}$ Emissions”, SAE Paper 940523.

Peters, N., “Turbulent Combustion”, Cambridge University Press, 2000.

Reitz, R. D., Bracco, F. B., “On the Dependence of Spray Angle and Other Spray Parameters on Nozzle Design and Operating Conditions”, SAE Paper 790494, 1979.

Siebers, D. L., "Scaling Liquid-Phase Fuel Penetration in Diesel Sprays Based on Mixing-Limited Vaporization”, SAE Paper 1999-01-0528, 1999.

Siebers, D. L., Higgins, B., "Flame Lift-Off on Direct-Injection Diesel Sprays Under Quiescent Conditions”, SAE Paper 2001-01-0530, 2001.

Turns, S. R., "An Introduction to Combustion: Concepts and Applications”, McGraw-Hill, 1996. 